Vol. VIII, n. ${ }^{0} 1$ (invierno 2020), pp. 9-18, ISSN: 2255-4505

\title{
INTRODUCCIÓN. LA TEORÍA LITERARIA, HOY: HACIA LA POROSIDAD DE LAS FRONTERAS
}

\author{
INTRODUCTION. LITERARY THEORY TODAY: \\ TOWARDS THE POROSITY OF BORDERS \\ GUILLERMO SÁNCHEZ UNGIDOS \\ Universidad de Oviedo \\ sanchezguillermo@uniovi.es
}

\begin{abstract}
Lo que intento hacer aquí es ilustrar el modo en que la teoría -0 , mejor dicho, reforjar constantemente el pasadizo entre la teoría y la práctica- me proporciona subidones similares a los que se describen como pelotazos de heroína.
\end{abstract}

Stewart Home, Memphis Underground

"Durante todo el día mientras estoy trabajando soy increíblemente consciente [...] de lo frágil que es todo, el mecanismo de la visión humana y la capacidad de ver las cosas, de lo fácil que puede perderse" (Foster Wallace 2015: 51-52). Estas lúcidas palabras escritas por David Foster Wallace pueden servirnos de introducción a la "esencia teórica" (Gadamer 2000: 28) que jalona este monográfico, que nace de la predisposición a explorar el espacio teórico entre sujeto y objeto que permite experimentar lo otro no como lo otro, un límite del ser consigo mismo, sino como una ampliación de las posibilidades de lectura de nuestro mundo, como una ruptura de la obstinación a través de la cual reconocemos lo que nos rodea y, por ende, a nosotros mismos. Esta es la "esencia" de lo que deberíamos llamar "teoría": es ver lo que es, en el sentido originario de la contemplación, es estar presente. Así lo entiende Gadamer: "Prescindiendo de sí, mirando lo que es: esta es la forma de una conciencia ilustrada [...]. No debe ser una conciencia educada a través de la ciencia y para la ciencia; debe ser solo una conciencia humana educada que ha aprendido a pensar el punto de vista del otro y a buscar la comprensión sobre lo colectivo y lo común" (2000: 43).

En este sentido, no se trata tan solo de reconocer el interés por realizar aproximaciones parciales basadas en este modo de ver, sino de hacerlo dialogando con las numerosas lecturas transversales que se están dando en el panorama de la teoría literaria. De entrada, estas páginas responden a ello con una doble función: la de recoger ocho propuestas teóricas de actualidad basadas en 
esa premisa y la de satisfacer la necesidad de sintetizar un camino común -una forma de resistencia frente a aquellas consignas que entienden el pensamiento con impotencia- que amplía y reformula nuestra condición hermenéutica.

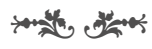

La extensión de un modelo total, único y compartido de interpretación y valoración de los productos artísticos es totalmente fallida; es en este terreno en el que lo teórico es una "ilusión vanidosa", por decirlo con palabras de Steiner: "Invocar y desarrollar una 'teoría de la crítica', una hermenéutica y una poética teórica en relación con las formas significantes de lo textual y lo estético, solo en el sentido metafórico o mimético más escrupulosamente reconocido, es 'traducir', 'ser traducido'" (1991: 93-94). "[E]l simple apelativo de 'teoría'", señala Jonathan Culler (2000a: 13), "ha pasado a designar aquellas obras que han supuesto un reto a la forma de pensar más común en campos de estudio diferentes a los que en apariencia le son más propios", que se atreven a indagar más allá proporcionando un análisis del sujeto, el lenguaje, la historia, el medio o el espacio para ofrecer nuevas explicaciones a los problemas textuales y culturales: "Esta es la explicación más sencilla de qué convierte a un texto en teoría; las obras que se consideran teoría producen efectos más allá de su ámbito original" (2000a: 13). Esta mirada legitima ciertas prácticas que la literatura en sí misma despierta, dotándolas de entidad teórica y ontológica: la eliminación de la exigencia de inteligibilidad directa, la reflexión sobre qué suscitan esos medios de expresión y la atención a cómo se producen significados y consecuencias afectivas (Culler 2000a: 55); "la llave 'original' hará que descubramos algo más acerca de la obra, algo más que la mera copia de la llave no nos aportaría jamás: la teoría hace que podamos entender el ejemplo (la obra), pero la obra hará que podamos también entender algo nuevo acera de la teoría y sus contextos" (Fernández Mallo 2018: 296).

Ante la sucesión fragmentaria de distintas encrucijadas que ha tratado de abrir nuevas vías epistemológicas y nuevos diálogos (Casas 2014: 17), el efecto de la intervención teórica en y desde esos "otros espacios" describe un panorama de agotamiento en los límites de nuevas hipótesis y metadiscursos, atravesándolos y dotándolos de otro tipo de exigencias. La teoría, consciente de que habita un "espacio cultural muy polémico en el que lo que ha importado para la continuidad y transmisión de conocimientos ha sido el significante, entendido como un acontecimiento que ha dejado rastros perdurables sobre el sujeto humano" (Said 2004: 301), se construye también, en esencia, "como confluencia y armonización de disciplinas diversas" (Núñez Ramos 2008: 339), integrando de manera crítica herramientas, métodos y puntos de vista procedentes de otros campos del saber sin perder su identidad y ampliando su actuación hacia estos mismos dominios, dando lugar a "conceptos viajeros" (Bal 2009) que, al desplazarse, enriquecen tanto su propio significado como aquellas disciplinas entre las que transitan. 
La investigación específica y la producción del propio sistema mediático y cultural han demostrado también que la literatura ha cambiado su posición y su función en el saber humanístico, dando paso a una "continuidad epistemológica" (Mora 2012: 101) que amplía su horizonte, cuya constitución como artefacto cultural no se reduce al texto escrito, sino que atañe a todas las dimensiones de la persona que lo materializa, de ahí que se proyecte sobre cualquier ámbito de la experiencia y lo incorpore como ingrediente de sus creaciones.

$\mathrm{Si}$, como señala Culler, el objeto de la teoría lo han de constituir las "prácticas significativas" (2000a: 59), la producción y representación de la experiencia y la constitución de los sujetos humanos, estas tentativas (literarias) son necesariamente transversales, "textos presentados como fenómenos" (Fernández Porta 2010: 10), ofrecidos por el artista como una invitación a la hibridación activa de los saberes: el estado natural del conocimiento humano. Es preciso, por tanto, cartografiar esas prácticas de escritura transversal, que responden a una sensibilidad "provocativamente pluralista" (Sontag 2019: 386) que, además de ir más allá de los géneros, busca una unidad entre experiencia y conocimiento, a través del diálogo sereno entre estética e ideología, literatura y sociedad. Pero lo más decisivo es que cualquier ejercicio hermenéutico con el que afrontarlas requiere cierta "solidaridad", entendida, según Rorty (1991: 207-211), como la identificación imaginativa con la alteridad constituyente de nuestro ser.

Por tanto, la consolidación de la teoría en el ámbito académico pasa por "explorar nuevos dominios de estudio, elaborar nuevos objetos de conocimiento y responder así al incesante movimiento de lo real literario y sus márgenes en el mundo presente, donde alcanza su sentido el proceso de mundialización vivido y el ciberespacio" (Chicharro Chamorro 2017: 37). Todo ello parece demandar un enfoque consciente de las estrategias que explican la generación de un campo teórico y cultural propio, la actualización del aparato crítico para realizar la correspondiente ligazón con esa "nueva teoría" que surgiría de las "nuevas prácticas". Y es que, como afirma Javier García Rodríguez, "[l]a crítica, garante de un discurso que tiene en su médula el gen de la transformación (también la transformación social), está obligada a renovarse para ser capaz de inscribir en el campo literario un discurso que se mueve siempre en el riesgo de no ser, en la posibilidad de no decir" (2017: 119-120). Revivimos, así, a través de perspectivas polifónicas y divergentes, dos cuestiones fundamentales del trabajo teórico: la inevitabilidad y la utilidad de la teoría, por un lado; y, por otro, su lugar y su función social, una relación entre sujeto y objeto "que no se conforma en función de una oposición vertical y binaria entre los dos, sino que tiene como modelo la interacción, en el sentido que tiene el término 'interactividad'" (Bal 2009: 37), en un contexto en el que además conviven asentados en sociedad distintos tipos de lenguajes y sistemas simbólico-discursivos, verbales y no verbales.

Este monográfico pretende abarcar, dentro del dominio hispánico, todos los aspectos en que la teoría y la literatura se constituyen y definen como espacios de confluencia con otros ámbitos del saber y de la vida. Teniendo en cuenta que la producción, el desarrollo y la atención a estas prácticas han adquirido cierta importancia y han aumentado notablemente en nuestro entorno cultural, no 
se trata únicamente de establecer relaciones entre disciplinas o formas artísticas, sino de estudiar cómo la teoría y la literatura están atravesadas por elementos y categorías de otros medios que los unifican y, viceversa, cómo la literatura y su teoría ocupan y enriquecen esos otros ámbitos, con el convencimiento de que "if the literary can function as exemplary representation of agency for theory it can also be a source of agency in theory, as literary works provide leverage for theoretical argument" (Culler 2000b: 284). Los textos que presentamos aquí exploran y cuestionan críticamente las relaciones entre las dinámicas culturales y los compartimentos del saber, el funcionamiento de las categorías a través de las cuales el sujeto intenta entender los productos culturales, allí donde se asienta un inconsciente ideológico de interpretación, a través del análisis de textos o artefactos emergentes en diferentes territorios, medios y espacios fronterizos.

En esta zona de encrucijada teórica se sitúa Laro del Río Castañeda en el artículo "Las fronteras invisibles de Magical Girl. Narración aleatoria y mitologías incomprendidas en la representación de una identidad nacional". Partiendo de un enfoque rizomático, con el convencimiento de que la ambigüedad necesita pluralizar y aunar diferentes posturas teóricas, se abordan aquí aquellos espacios "rugosos" del filme de Carlos Vermut que constituyen narrativamente una identidad española "agujereada", más allá de lo local. Las premisas de Michel de Certeau acerca de lo cotidiano, la hospitalidad derrideana o el materialismo aleatorio de Althusser le sirven al autor para explorar, a pie de pantalla, las "fronteras invisibles" (estatales, de género, médicas, económicas y generacionales) que apuntalan el engranaje narrativo en un Madrid heterotópico, que constatan el tránsito de las diferentes mitologías deformadas hacia una identidad nacional forjada en la tensión entre lo público y lo privado, entre el pacto social y lo individual, pues es en estas fronteras donde los personajes, al entrar en conflicto, fabulan la realidad, desarrollan la otredad y desacralizan el mito. En este constante encuentro con los otros, se dibuja, según el autor, una línea de incomprensiones y "oquedades" entrecruzadas por las que los personajes, sin saber que están siendo constituidos por ellas, transitan aleatoriamente, creando una irreparable tensión que apuntala una idea abstracta de la identidad nacional, "agujereada", invisible y, por supuesto, incomprensible para los personajes del filme.

Las diferentes mitologías y su contraste con el espacio y los objetos materiales que lo conforman son un desencadenante de la acción de muchos relatos; y esbozan un retrato de los personajes, y de los lectores, que (des)mitifica una realidad que no pueden aprehender en su totalidad. La intimidad se subjetiviza y se concreta en un tejido social que permite la reconstrucción de las individualidades y que determina las interrelaciones con otros códigos ideológicos y culturales. Sobre ello, y más en concreto sobre la realización de una "escritura femenina" en el espacio narrativo, nos ilustra Rosa M. ${ }^{a}$ Calero Jurado en "La construcción del sujeto femenino a través del espacio narrativo en dos novelas contemporáneas". En este trabajo, la autora centra su análisis en la configuración del discurso espacial como localización y ecosistema propicio a la construcción del sujeto femenino, un orden simbólico alternativo amparado en la deconstrucción del orden hegemónico establecido en el propio acto de narrar, que de 
por sí implica una toma de posición y una responsabilidad. La autora realiza una aproximación teórica a La plaza del diamante, de Mercè Rodoreda, e Irse de casa, de Carmen Martín Gaite, para constatar que la ciudad penetra por los poros de la narración y ayuda a las protagonistas a tejer y destejer su psicogeografía para construir su identidad como contrapunto. Tanto los espacios privados como los espacios públicos son traídos a colación en este artículo para explorar cómo se constituye ese proceso de deconstrucción que favorece una dialéctica entre pasado y presente, necesaria para la (re)construcción de una identidad femenina que reconquista el espacio que le fue privado.

Estas premisas teóricas acerca de la deconstrucción del modelo hegemónico impuesto y la posterior reconstrucción de una identidad propia por parte del sujeto femenino aparecen también en "Contra la 'verdad': 4.48 Psychosis y Clavícula como narraciones femeninas del dolor, la locura y el suicidio". Juan Pedro Martín Villarreal teoriza aquí sobre las experiencias femeninas del dolor la locura y el suicidio representadas en la literatura, que han desarrollado una postura contra el régimen de verdad establecido por el discurso médico desde el siglo xIX. Perspectivas teóricas como la Michel Foucault sirven de piedra de toque en este estudio para analizar cómo la escritura femenina constituye un espacio contestatario y crítico con respecto a las verdades monolíticas de la medicina, la psicología y la psiquiatría, que esconden la cara oculta, ideológica, de las diferentes patologías; una forma de resistencia frente al ejercicio del "biopoder" y la construcción de este régimen único de verdad. El artículo explora las oportunidades que a este respecto ofrecen la obra teatral de Sarah Kane, 4.48 Psychosis, y la novela de Marta Sanz, Clavícula, dos alternativas artísticas que reivindican la mujer como sujeto doliente que intenta aprehender un dolor no hegemónico, convivir con él, "espectacularizarlo" y evidenciarlo con la muerte, negando un origen o una razón directa. El autor, consciente de la estructura híbrida de las obras, se detiene así en unas escrituras del yo que comparten algunos elementos de los discursos que propician la patologización del suicidio, el dolor o la locura como enfermedades (la fragmentación de la identidad femenina, la causalidad amorosa como origen, su propia feminización, el intento de darle una forma concreta, etc.) para revertirlos, para ironizarlos y protestar -políticamente- contra la autoridad del "biopoder", la vigilancia y el control de los cuerpos, extendiendo las sensaciones del sujeto femenino, desenmascarando las intenciones ideológicas, apelando al lector, desde la narración y la representación de otros discursos como el clínico.

La experiencia narrativa puede devenir, entonces, en pensamiento, una formulación teórica contra las prácticas organizadas, sistemáticas y recurrentes, que reacciona a las maneras de decir y hacer en las que un sujeto se exhibe y obra en tanto sujeto de conocimiento, sujeto social, sujeto crítico y sujeto ético, estableciendo modelos en los que puede reconocerse como sujeto de esa experiencia, regulando la relación consigo mismo y con los otros. En este contexto, en que toda experiencia es históricamente singular y actúa performativamente en tanto que instaura una racionalidad, Alfredo Poggi plantea en "Hacia una teoría literaria post-secular: repensando la crítica liberal de la religión a través de 
Flora Tristán, Paul Gauguin y Vargas Llosa en El paraíso en la otra esquina" una aproximación a la obra del autor peruano basada en una crítica de la religión que unifica la narrativa y cuestiona la oposición entre lo religioso y lo secular. A partir de una revisión a los estudios de la (post-)secularización de Habermas, Casanova y Taylor, se aborda teóricamente la unificación de las historias de Flora Tristán y Paul Gauguin, en cuyo desarrollo narrativo encontramos dos formas de afrontar la religiosidad. El autor propone una postura crítica que nos invita a leer la obra desde una perspectiva "post-secular" que muestra la ambigüedad y la complejidad de una realidad religiosa que nos lleva a traspasar las fronteras de las oposiciones binarias esencialistas, transhistóricas y transculturales del liberalismo. Su interés reside, precisamente, en el acercamiento teórico a la narración fundamentado en las formas de interacción entre lo secular y lo religioso, del que resulta una nueva configuración en red del saber y del poder $y$, en consecuencia, una nueva forma de experiencia también fronteriza.

El intento de topografiar superficies tan ásperas como estas supone una provocación amistosa a mostrar las fallas, grietas y resquebrajamientos en un sistema necesariamente abierto que se ha de nutrir de todo aquello con lo que convive, un punto de fuga que evidencia así la imposibilidad de establecer un único contexto seguro y saturado que determine un sentido preciso al texto. Consciente de ello es Noelia S. García, que propone en su artículo "Teoría utópica y espacio urbano. El sueño de la ciudad ideal en la narrativa española" una lectura teórica de la utopía literaria como "género fronterizo", que necesariamente -porque así se configura- se ha de entender en relación con otras disciplinas, como manifestación, además, de ruptura con el orden establecido mediante la desestructuración de la jerarquía entre lo real y lo imaginario. La autora realiza un recorrido pormenorizado por la representación utópica en la narrativa española para llegar a casos contemporáneos como los de El Dorado, de Robert Juan-Cantavella, cuyo modelo utópico, codificado en el "no lugar" de Marc Augé, el de la ciudad de vacaciones, se estudia en relación con las políticas neoliberales y el sueño al que aspirar. Constatando la vigencia de las nociones tanto de "lugar" como de "no lugar", abre así una nueva vía de exploración de la ciudad literaria como utopía, ese espacio de ensoñación que permite lograr más movimiento y mayor libertad en la representación, que en el texto el mundo esté al margen de cualquier voz narrativa, pero a la vez que la pluralidad se vea reflejada en él como una forma de vida en un espacio de interferencia de tradiciones y estilos derivados de una época, como un paseo por materialidades textuales hibridadas.

Y es que hay obras que nos exigen mirar no solo al presente, sino también al pasado y al futuro, entrar en ellas con una atención crítica que resista a la constante interpelación de unos provocativos ofrecimientos a caballo entre diversos códigos, necesariamente interrelacionados, que exigen (re)pensar teóricamente determinadas obras móviles que realizan un camino entre las ruinas de la realidad social y la memoria. A ello nos encomienda Sheila Pastor en su trabajo "Trazas y trizas del viaje: Poste restante, de Cynthia Rimsky, modelo textovisual", donde propone una lectura fronteriza de la obra polimórfica de la autora 
chilena, cuya configuración, basada en el uso de la imagen y el fragmento, en la unión entre montaje, diseño y palabra escrita, propone una poética del tránsito de naturaleza textovisual, en cuyo proceso de creación se va desplegando, a su vez, una particular relación entre sujeto, mundo y arte. En primer lugar, el estudio de las tres ediciones chilenas de Poste restante sirve para acentuar la configuración miscelánea, híbrida e intermedial del texto viajero en cuya voluntad autorial también intuimos una intención de repensar en el devenir el propio género. Esta premisa, en la que se da constancia de que las distintas hibridaciones textuales se relacionan simbióticamente, desencadena una reflexión acerca del desplazamiento como búsqueda de la individualidad y como ejercicio de creación artística al mismo tiempo, que pone en jaque al lector. Esta actitud artística "radicante", como sugiere la autora, no agota la respuesta sobre las posibilidades de un texto intermedial, sino que se enfrenta como núcleo del hecho literario, como una variación de la experiencia humana en su representación artística que simboliza la comunicación con el pasado y el presente.

Los modos de narrar, resistir y desviar parten de la convivencia de distintas formas discursivas relacionadas con los lenguajes, las mitologías y la cultura que nos rodean y que actualizan de manera continua los relatos de nuestro tiempo. Los escritores, agentes de producción simbólica, actúan desde un entendimiento de los procesos mediáticos entonando su propia melodía y estableciendo un pacto de lectura basado en la exploración y la reflexión de las posibilidades hermenéuticas del texto literario como punto de encuentro. Lo constatan narrativas plurales como la de Javier Marías, en la órbita de una fenomenología visual, como apunta Carmen María López López en "Amar de verdad los textos: hibridaciones fílmicas en la escritura de Javier Marías". Partiendo de la "traducción intersemiótica" de Roman Jakobson, aborda las posibilidades sígnicas y la confluencia entre el sistema literario y el sistema cinematográfico en la escritura del autor de Todas las almas, Corazón tan blanco o Mañana en la batalla piensa en mí. López López, en contraste con otros documentos visuales incluidos en sus novelas y en busca de una poética fílmica como punto clave en la obra de Marías, estudia uno de los aspectos menos trabajados en torno a su escritura: el modo en que el texto cinematográfico se transfiere hermenéuticamente al medio de la palabra escrita, a partir de la verbalización, la pluralidad y la superposición. Como propone la autora, la riqueza del modelo textovisual desarrollado por Marías reside en una mirada fenomenológica que no le dé importancia a la jerarquía entre palabra e imagen, sino que se superpongan en la narrativa para acoger el diálogo intersemiótico y el pensamiento teórico sobre el mismo.

Palabra, imagen, percepción, creación y técnica se entrecruzan así para responder a un mismo propósito: interpretar el mundo. En la literatura, se recogen estímulos de naturaleza semiótica diversa para teorizar sobre lo que nos rodea, ofreciendo un arco de posibilidades estimulante y sugestivo. Repensar los discursos desde esta perspectiva implica entendernos a nosotros mismos en un ensamblaje en el que nuestros deseos y habilidades, nuestras técnicas y nuestras ideas, están en perpetua movilidad y recombinación, formando textos que nos arman y nos desarman simultáneamente. Es el caso también de la poesía, a la 
que se dedica José Ángel Baños Saldaña en su texto "Metapoesía y publicidad: el poeta en la sociedad de consumo". Bajo el paraguas de las reflexiones metapoéticas y metaliterarias, enclave poético a partir del siglo xx, el autor aborda las relaciones entre poesía y publicidad en el contexto mediático. Se atiende aquí a ejemplos concretos de la lírica contemporánea que insertan el eslogan en una propuesta de poética personal, que utilizan el texto publicitario para realizar una sátira social, que se sirven de la publicidad de a pie y que reelaboran el lenguaje de la compraventa para construir un modelo interpretativo que tenga en cuenta que la construcción del poema no se reduce a la intertextualidad, sino que se revela $-y$ se rebela- en la interferencia entre diferentes discursos. Los poemas de Juan Bonilla, Ángel González, Roger Wolfe, José Alcaraz, Jorge Riechmann o Aurora Luque refuerzan los vínculos entre lector y autor y traen a colación, en la transversalidad genérica, los debates ontológicos y epistemológicos acerca del lenguaje literario y su función en la sociedad.

Como vemos, los artículos de este monográfico atienden a la disolución de las fronteras tradicionales y a la evidencia de un discurso estético en intersección que estructura su propia problemática artística como un "espacio de complejidad hermenéutica donde las diferencias son no solo reconocidas y comprendidas sino asimismo intercambiadas y discutidas" (Pozuelo Yvancos 2009: 96). El componente que surge de ellas tiene que ver con la complejidad de las situaciones histórico-éticas a las que creadores y lectores responden, con el convencimiento de que "no puede haber divorcio entre el arte y las formas de la vida social. Obras de arte, formas psicológicas y formas sociales se reflejan mutuamente, y cada una cambia cuando cambian las otras" (Sontag 2019: 280). Por tanto, es esencial para el valor estético actualizarse en una dialéctica que reúna la particularidad de su constitución heterogénea y una universalidad radicada en los sustratos más profundos de la existencia humana.

En el doble dilema ontológico y epistemológico que plantean estos productos, no se renuncia a la experiencia estética, sino que se incide en el propio acto creativo, en su dimensión productiva y en su dimensión hermenéutica, a través de su condición transversal, pues solo con este recurso "se puede alcanzar una explicación unitaria e integrada de las distintas propiedades y funciones que comúnmente se atribuyen a la literatura", así como "a las destrezas, recursos y capacidades que el ser humano emplea para hacer frente a los textos literarios, las mismas que utiliza en otros muchos aspectos de la vida, pero en ese caso potenciadas por las propiedades estructurales del estímulo" (Núñez Ramos 2008: 339).

Las aproximaciones teóricas que en estas páginas acontecen no nacen únicamente con el propósito de llevar a cabo una auténtica recuperación del significado y de la función de la teoría, sino que además tratan de "combatir la banalidad y los excesos estéticos de una hermenéutica de la cultura infinita y autocomplaciente, sin por ello perder el sentido del sentido, la capacidad para discernir y apreciar los valores cognitivos y afectivos, éticos y estéticos" (González de Ávila 2010: 13). Se intuye, a través de los artículos aquí publicados, la implicación de los saberes científicos en la construcción de una "crítica ética" (Booth 
2005) capaz de superar también cualquier espacio insondable entre el trabajo de la teoría y el trabajo de la creación; en suma, entre el pensamiento y el sujeto.

Con este monográfico emplazamos a los lectores a visitar un bazar que "acerca violentamente unas a otras las cosas más dispares, lo más exótico y lo más familiar, lo gigantesco y lo minúsculo, la naturaleza y los productos de la civilización humana" (Spitzer 1961: 258), donde el paradigma de moda no puede legitimar tan fácil discursos o acercamientos críticos totales al arte, pues este se codifica en una solución dialéctica basada en la complejidad que asedia las nociones más tradicionales a fin de rellenar el hueco entre teoría y experiencia: solo de esa forma se puede afirmar la operatividad, usando la teoría en la convivencia de tradiciones y estilos para abordar la aparición de caminos estéticos construidos en mayor o menor grado al costado de las vicisitudes sociales y populares derivadas de esta época. Abrimos una línea intelectual manifestada a través de distintos lenguajes, discursos y sujetos, que responde a las sensibilidades contemporáneas y que trata de mostrar y establecer una nueva forma de leerlas e interpretarlas basada en una explotación fructífera y responsable de la multiplicidad para fomentar una comprensión auténtica y así enriquecer y transformar el proyecto teórico, seguros de que con ello "every perspective expressed in a symbolic language becomes a 'terministic screen' which both reveals some truths -obviously 'demonstrated' to anyone employing the language- and conceals others" (Booth 1979: 107).

Presentamos el resultado de un movimiento nómada entre disciplinas, espacios, referentes, discursos y textualidades, como consecuencia de un acto creativo en paralelo a todas esas cuestiones, atravesado por voces teóricas singulares y por las propias experiencias estéticas que surgen al afrontar una valiente postura intelectual que nos predispone a aceptar la inevitable y necesaria porosidad de las fronteras.

\section{OBRAS CITADAS}

Bal, Mieke (2009): Conceptos viajeros en las humanidades. Una guía de viaje. Murcia, CENDEAC.

Booth, Wayne C. (1979): Cirtical Understanding. The Powers and Limits of Pluralism. Chicago, University of Chicago Press.

- (2005): Las compañías que elegimos. Una ética para la ficción. México, Fondo de Cultura Económica.

Casas, Arturo (2014): "Efectos (pos-)teoría y reflexividad epistemológica", Tropelías. Revista de Teoría de la Literatura y Literatura Comparada, n. ${ }^{\circ} 22$, pp. 17-32.

Chicharro Chamorro, Antonio (2017): "Aspectos del ordenamiento jurídico en España de la institución área de conocimiento de teoría de la literatura y literatura comparada", Tropelías. Revista de Teoría de la Literatura y Literatura Comparada, número extraordinario 2, pp. 21-38.

Culler, Jonathan (2000a): Breve introducción a la teoría literaria. Barcelona, Crítica.

_ (2000b): "The literary in theory". En J. Butler, J. Guillory y K. Thomas (eds.): What's Left 
of Theory? New Work on the Politics of Literary Theory. Londres / NuevaYork, Routledge, pp. 273-292.

Fernández Mallo, Agustín (2018): Teoría general de la basura (cultura, apropiación, complejidad). Barcelona, Galaxia Gutenberg.

Fernández Porta, Eloy (2010): Afterpop. La literatura de la implosión mediática. Barcelona, Anagrama.

Foster Wallace, David (2015): "Otro ejemplo más de la porosidad de ciertas fronteras (XI)". En: Entrevistas breves con hombres repulsivos. Barcelona, Debolsillo, pp. 51-52.

Gadamer, Hans-Georg (2000): "Elogio de la teoría". En: Elogio de la teoría. Discurso y artículos. Barcelona, Península, pp. 23-43.

García Rodríguez, Javier (2017): "Cultura del post y sociedad Thermomix" ${ }^{\mathrm{TM}}$ : géneros literarios y consumo". En: Literatura con paradiña. Hacia una crítica de la razón crítica. Salamanca, Delirio, pp. 115-126.

González de Ávila, Manuel (2010): Cultura y razón. Antropología de la literatura y de la imagen. Barcelona, Anthropos.

Mora, Vicente Luis (2012): El lectoespectador. Barcelona, Seix Barral.

Núñez Ramos, Rafael (2008): "La teoría de la literatura, encrucijada interdisciplinar". En J. A. Calzón García et al. (eds.): Actas del I Congreso Internacional de filología hispánica: Jóvenes investigadores. Oviedo, Universidad de Oviedo, pp. 329-340.

Pozuelo Yvancos, José María (2009): "Razones para un canon hispánico", Signa: Revista de la Asociación Española de Semiótica, n. 18, pp. 87-97.

Rorty, Richard (1991): Contingencia, ironía y solidaridad. Barcelona, Paidós.

Said, Edward W. (2004): El mundo, el texto y el crítico. Barcelona, Debate.

Sontag, Susan (2019): "Una cultura y una nueva sensibilidad". En: Contra la interpretación y otros ensayos. Barcelona, Debolsillo, pp. 373-386.

Spitzer, Leo (1961): "La enumeración caótica en la poesía moderna". En: Lingüística e historia literaria. Madrid, Gredos, pp. 247-290.

Steiner, George (1991): Presencias reales. Barcelona, Destino. 